\title{
Reversion of fruit-dependent inhibition of flowering in Citrus requires sprouting of buds with epigenetically silenced CCMADS19
}

\author{
Carlos Mesejo $^{1 *}$ (D), Andrés Marzal ${ }^{1}$ (D), Amparo Martínez-Fuentes ${ }^{1}$ (D), Carmina Reig ${ }^{1}$ (D), Miguel de Lucas ${ }^{3}$ (D), \\ Domingo J. Iglesias ${ }^{4}$ (D), Eduardo Primo-Millo ${ }^{4}$, Miguel A. Blázquez ${ }^{2 *}$ (D) and Manuel Agustí ${ }^{*}$ (D) \\ ${ }^{1}$ Instituto Agroforestal Mediterráneo, Universitat Politècnica de València, València 46022, Spain; ${ }^{2}$ Instituto de Biología Molecular y Celular de Plantas, CSIC-UPV, València 46022, Spain; \\ ${ }^{3}$ Department of Biosciences, Durham University, Stockton Rd, Durham, DH1 3LE, UK; ${ }^{4}$ Centro de Citricultura y Producción Vegetal, IVIA-GV, Moncada, València 46113, Spain
}

\begin{abstract}
Authors for correspondence:
Manuel Agustí

Email:magusti@prv.upv.es

Miguel A. Blázquez

Email: mblazquez@ibmcp.upv.es
\end{abstract}

Received: 22 June 2021

Accepted: 10 August 2021

New Phytologist (2021)

doi: $10.1111 / \mathrm{nph} .17681$

Key words: alternate bearing, chromatin remodelling, Citrus spp., FLC, flowering, FT.

\section{Summary}

- In Citrus, the response to environmental floral inductive signals is inhibited by the presence of developing fruits. The mechanism involves epigenetic activation of the CCMADS19 locus (FLC orthologue), encoding a floral repressor.

- To understand how this epigenetic regulation is reverted to allow flowering in the following season, we have forced precocious sprouting of axillary buds in fruit-bearing shoots, and examined the competence to floral inductive signals of old and new leaves derived from them.

- We have found that CCMADS19 is enriched in repressive H3K27me3 marks in young, but not old leaves, revealing that axillary buds retain a silenced version of the floral repressor that is mitotically transmitted to the newly emerging leaves, which are able to induce flowering.

- Therefore, we propose that flowering in Citrus is necessarily preceded by vegetative sprouting, so that the competence to respond to floral inductive signals is reset in the new leaves.

\section{Introduction}

Plants growing in temperate climates align their reproductive cycles with the seasons. The optimal time of flowering is established through the integration of endogenous and exogenous information, which is remembered through a mechanism that converges on the dynamic deposition and removal of epigenetic marks in key integrator genes (reviewed in Andrés \& Coupland, 2012 and Bratzel \& Turck, 2015). For instance, in annual plants that require vernalisation to flower, such as Arabidopsis thaliana, cold temperature triggers flowering through epigenetic silencing of a floral repressor gene, FLOWERING LOCUS C (FLC) (Finnegan \& Dennis, 2007). This epigenetic repression is established by the Polycomb Repressive Complex 2 (PRC2) through trimethylation in Histone 3 Lys 27 (H3K27me3), which is targeted to the FLC locus by the VERNALIZATION INSENSITIVE3 (VIN3) homeodomain transcription factor (De Lucía et al., 2008). A critical step in this process is the restoration of the vernalisation requirement in the next generation. This is achieved during meiosis in the anthers, through epigenetic reprogramming of FLC by the jumonji-containing ELF6 protein,

*These authors contributed equally to this work. which directs $\mathrm{H} 3 \mathrm{~K} 27 \mathrm{me} 3$ demethylation in gametes (Crevillén et al., 2014).

In polycarpic plants, such as Arabis alpina, the FLC orthologue named PERPETUAL FLOWERING1 (PEPI) causes default repression of flowering in a similar mechanism to the one proposed for FLC (Wang et al., 2009). However, the degree of PEP1 stable silencing by vernalisation varies between meristems, therefore PEP 1 expression is reactivated during spring in some axillary meristems to promote vegetative growth and contribute to the polycarpic habit (Wang et al., 2009; Lázaro et al., 2018). This spatial difference between meristems indicates the key role of endogenous factors in the flowering process.

A particular case of endogenous control of flowering is observed in some cultivars of both evergreen and deciduous fruit tree species such as apple, avocado, mango, olive, pecan and pistachio, among others, and also in Citrus, in which the response to environmental floral inductive signals (i.e. cold temperature) is locally gated by the presence of developing fruits. Therefore, the fruits initiated in the previous season (ON season) block flowering in the following season (OFF season), and lead to a phenomenon called alternate bearing (Tuckey, 1922; Monselise \& Goldschmidt, 1982; Goldschmidt \& Sadka, 2021). As for FLC and PEP1, the fruit-mediated inhibition of flowering observed in 
Citrus is associated to epigenetic changes in CcMADS19 (the Citrus clementina FLC orthologue; Hou et al., 2014). Namely, the presence of the fruit is paralleled by (1) an enrichment of H3K4me3 mark in the CcMADS19 locus in the neighbouring leaves, (2) induction of CcMADS19 expression, and (3) subsequent repression of the Citrus FT orthologue (CiFT3, Ciclev10012905m, previously named CiFT2), during the floral induction period (Agustí et al., 2020). Although this mechanism explains the inhibition of flowering by fruits, it does not explain the necessary reprogramming that allows $\mathrm{ON}$ trees to flower in the next (OFF) season (Hoijemberg \& Cerdán, 2020).

In the present study, we established the hypothesis that the epigenetic activation of CcMADS19 in the leaf during the ON season is reset in the axillary buds, and, through cell divisions, transmitted to the new emerging leaves which then become competent to flower in the next OFF season. Our hypothesis is based on the following observations: (1) CcMADS19 expression in the buds from ON trees is low just before budbreak (Agustí et al., 2020); (2) these buds show enrichment of H3K27me3 in the CcMADS19 locus (Agustí et al., 2020); and (3) flowering in the OFF season is preceded by extensive sprouting and vegetative development of previously dormant buds (Verreyne \& Lovatt, 2009).

To test the above hypothesis, we used girdling, an experimental approach that induces precocious vegetative development in the axillary buds during the $\mathrm{ON}$ season before the cold inductive period (Agustí et al., 1992). This way, we can compare the effect of the floral inductive signals between old leaves and the new leaves derived from the buds in the presence of fruits.

\section{Materials and Methods}

\section{Plant material and growth conditions}

Experiments were carried out using field grown 10-yr-old trees of 'Nadorcott' mandarin (Citrus clementina Hort. ex Tan. $\times$ C. sinensis (L.)), grafted onto Carrizo citrange (C. sinensis (L.) Osbeck $\times$ Poncirus trifoliata (L.) Raf.) rootstock, and exhibiting a marked alternate bearing. Trees were planted $6 \mathrm{~m} \times 4 \mathrm{~m}$ apart, drip irrigated, fertilised and grown according to usual techniques. The experiment was carried out in a commercial orchard located in València (Spain).

\section{Experimental design and tree phenotyping}

The effect of fruit load on flowering was studied on 4 ON (fully loaded) and 4 OFF (without fruit) trees randomly selected according their uniformity in size and vigour. In a set of $16 \mathrm{ON}$ trees, a defruiting experiment was performed by removing $0 \%$, $33 \%, 66 \%$ and $100 \%$ of the developing fruits per tree at the onset of stage II of fruit development (July).

Flowering intensity was evaluated in early spring a few days before anthesis. Four branches distributed uniformly around the tree having some 300 nodes per branch were selected, and the number of sprouted nodes, shoots initiated and flowers per shoot were counted. From the number of shoots developed and the number of flowers per shoot, the total number of flowers could be calculated. The results were expressed in shoots and flowers per 100 nodes to compensate for the differences in size of the branches selected for counting. In summer and fall, vegetative shoots developed from the same branches were also counted, referring the results also per 100 nodes. Total yield per tree was determined by weighing all fruits at harvest (February).

Girdling experiments were performed in 200 leafy single flowered shoots $(\mathrm{ON})$ and vegetative shoots $(\mathrm{OFF})$ of 10 trees. ON shoots are determinate inflorescences with an apical fruit and 6-8 nodes along $15-25 \mathrm{~cm}$ which contain the axillary buds. Girdling was performed by removing a 2 - $\mathrm{mm}$ ring of bark from the peduncle $1 \mathrm{~cm}$ away from the calyx (Supporting Information Fig. S1). The effect of the date of girdling (early summer, late summer and early autumn) on sprouting and flowering was also assayed. Fruits from $\mathrm{ON}$ shoots that were not girdled served as controls. The days following girdling and in the next spring, axillary bud sprouting and flowering were evaluated in 50 shoots per treatment. The experiment was repeated in $2 \mathrm{yr}$.

Buds were sampled $7 \mathrm{~d}$ after girdling for IAA analysis by UPLC-MS/M. From October to January, leaves from ON, OFF and $\mathrm{ON}$-girdled shoots were collected for RNA extractions. Finally, the new shoots produced as a result of girdling were sampled in September for chromatin immunoprecipitation analysis. All samples were immediately ground and stored at $-80^{\circ} \mathrm{C}$ until analysed.

\section{Sequence analysis}

Amino acid sequences of the genes studied were obtained from the Phytozome v.13 database (www.phytozome.net). Multiple sequence alignment and phylogram analysis were carried out with the Clustal Omega tool at NCBI (www.ebi.ac.uk/Tools/msa/ clustalo/).

\section{Gene expression analysis}

Total RNA was isolated from frozen tissue using the RNeasy Plant Mini Kit (Qiagen, Hilden, Germany). RNA samples were treated with RNase free DNase (Qiagen) through column purification following manufacturer's instructions. RNA quality was tested by $\mathrm{OD}_{260} / \mathrm{OD}_{280}$ ratio and gel electrophoresis. RNA concentration was determined by fluorometric assays with the RiboGreen dye (Molecular Probes, Eugene, OR, USA) according to manufacturer's instructions. cDNA was obtained from $1 \mu \mathrm{g}$ total RNA using the QuantiTect ${ }^{\circledR}$ Reverse Transcription Kit (Qiagen, USA) in a total volume of $20 \mu$ l. Quantitative real-time PCR was carried out on a Rotor Gene Q 5-Plex (Qiagen) using the QuantiTect ${ }^{\mathbb{B}}$ SYBR $^{\mathbb{B}}$ Green PCR Kit (Qiagen). The reaction mix and conditions followed the manufacturer's instructions with certain modifications. The PCR mix contained $2.5 \mu \mathrm{l}$ of a 4-fold cDNA dilution, $12.5 \mu \mathrm{l}$ of QuantiTect ${ }^{\circledR}$ SYBR Green PCR Master Mix (Qiagen), $1.5 \mu \mathrm{l}$ of $0.3 \mu \mathrm{M}$ primer F, and $1.5 \mu \mathrm{l}$ of $0.3 \mu \mathrm{M}$ primer $\mathrm{R}$, the final volume being $25 \mu \mathrm{l}$. The cycling protocol for the amplification consisted of $15 \mathrm{~min}$ at $95^{\circ} \mathrm{C}$ for preincubation, then 40 cycles of $15 \mathrm{~s}$ at $94^{\circ} \mathrm{C}$ for denaturation, $30 \mathrm{~s}$ at 
$60^{\circ} \mathrm{C}$ for annealing and $30 \mathrm{~s}$ at $72^{\circ} \mathrm{C}$ for extension. The sequences of the primers used are presented in Table S1.

\section{Chromatin immunoprecipitation}

ChIP was performed as previously described (Lee et al., 2007) with the following modifications. The crude nuclear pellet was resuspended in nuclear lysis buffer and sonicated in a Covaris M220 focused-ultrasonicator for $8 \mathrm{~min}$ at $6^{\circ} \mathrm{C}$ with a $5 \%$ duty factor. The soluble chromatin solution was incubated with $1 \mu \mathrm{g}$ of anti-H3K27me3 (Millipore 07-449) for $4 \mathrm{~h}$, and chromatinantibodies complexes were captured with protein $A / G$ magnetic beads (Thermo Scientific). De-crosslinking reaction was performed with Chelex slurry (Bio-Rad) as described (Nelson et al., 2006).

For the identification of the $\mathrm{H} 3 \mathrm{~K} 27 \mathrm{me} 3$ regulated regions, we first divided the CcMADS19 promoter (5000 bp) and genomic region $(13800 \mathrm{bp})$ in bins of $1000 \mathrm{bp}$, and designed primers to amplify $c .180 \mathrm{bp}$ within each bin. In total, 19 pairs of primers were screened by qPCR against the input. We then performed a comparative analysis between induced and noninduced samples.

\section{Statistical analysis}

STATGRAPHICS PLUS software was used to analyse the data. Analysis of variance (ANOVA) was performed using Fisher's least significant difference test for mean separations at $P<0.05$.

\section{Results and Discussion}

\section{Restarting vegetative growth in ON shoots allows flowering}

Under temperate climate conditions, Citrus trees flower and set fruits only once a year, in spring. But they sprout again in summer-autumn, only producing vegetative shoots. This latter sprouting is important because floral shoots of the next season in spring develop mainly on these vegetative shoots (Guardiola et al., 1982). It has been proposed that the presence of fruits not only represses flowering but also vegetative sprouting (Verreynne \& Lovatt, 2009; Martínez-Fuentes et al., 2010). Accordingly, we observed that early fruit removal (July) significantly increased bud sprouting in summer-autumn and next spring, and also flowering, the intensity of which depended on the defruiting intensity (Fig. 1a,b). Interestingly, control trees (i.e. ON) were able to only produce five shoots per 100 nodes in summer/fall, and 17 in spring (Fig. 1a), bearing practically no flowers (Fig. 1b). Conversely, thinning 66\% and 100\% of fruits increased summer-autumn sprouting up to eight and 18 shoots per 100 nodes, respectively (Fig. 1a), and significantly boosted flowering (Fig. 1b). In summary, during an $\mathrm{ON}$ season the axillary bud sprouting is very low, and its flowering-ability results are abolished due to the epigenetic activation of the CcMADS19 gene in the leaves (Agustí et al., 2020).

To further understand the role of sprouting in the resetting of the flowering ability after the ON season, and CcMADS19 reprogramming, we focused on the short-distance effect caused by the fruit to the lateral buds. Citrus trees set fruits in the apical position of determinate inflorescences, and girdling reverts the inhibitory effect on proximal bud sprouting (Martínez-Fuentes et al., 2010). In fact, girdling or ringing branches in midsummer is used to mitigate biennial bearing when performed in the OFF year (Agustí et al., 1992; Goren et al., 2010). Accordingly, fruitpeduncle girdling in early (G1) and late (G2) summer allowed sprouting of the first three or four nodes of the eight nodes closest to the girdle (Fig. 2). Moreover, it has been proposed that sprouting inhibition is mediated by the outbound flux of auxin from the fruit (Bangerth et al., 2000; Krasniqi et al., 2013). Consequently, the girdling-promoted sprouting correlated with a decrease in auxin levels in the shoot (Fig. S2), which is in agreement with the report that girdling impairs polar auxin transport (Ferguson \& Beveridge, 2009). A few days after girdling in early and late summer, lateral buds sprouted, achieving $22 \%$ in the second date of treatment (G2), whereas ON shoots girdled in the third date (G3, early autumn), and ungirdled ON shoots did not sprout. Nonbearing branches (OFF) sprouted naturally up to $27 \%$ in July and September (Fig. 3). As expected, all the sprouted
Fig. 1 Effect of fruit removal on the summerautumn and following spring bud sprouting (a) and flowering (b) of tangor 'Nadorcott' (Citrus clementina $\times$ Citrus sinensis). Defruiting was performed in early summer. Values are the average of four trees per treatment. Different letters indicate statistically significant differences $(P<0.01)$.
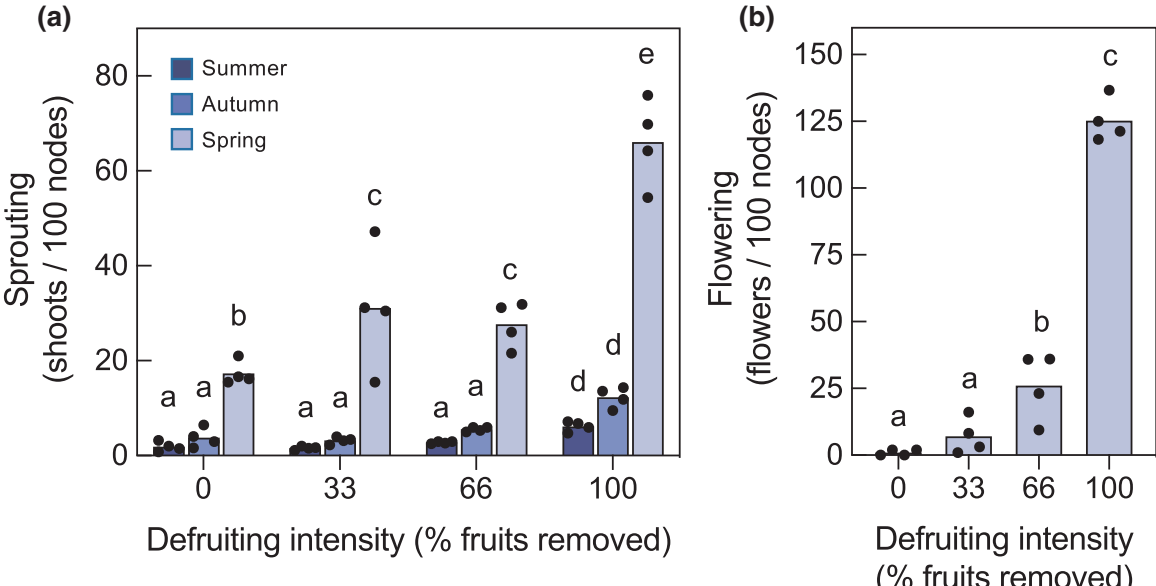


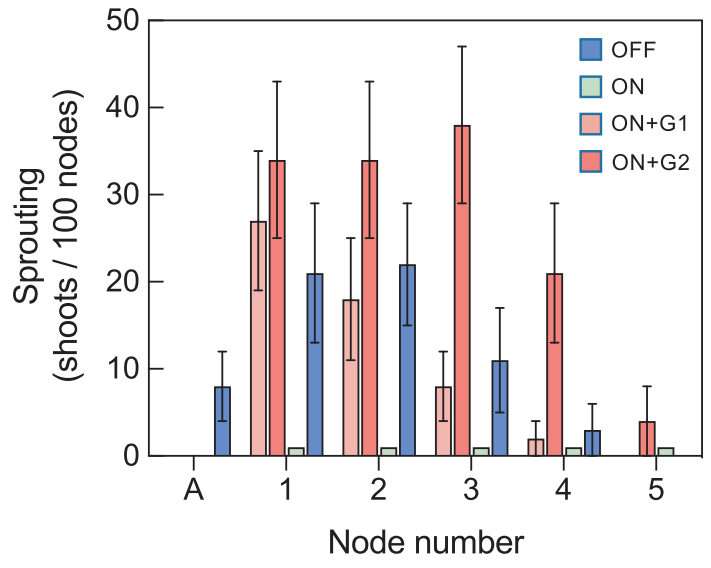

Fig. 2 Effect of fruit-peduncle girdling on axillary bud sprouting along the shoot of tangor 'Nadorcott' (Citrus clementina $\times$ Citrus sinensis). Girdling was performed on early summer (G1) and late summer (G2). Data are means \pm standard error of 50 shoots per treatment distributed in 10 trees. ON: shoot with an apical fruit; OFF: shoot without fruit.

buds produced only vegetative shoots. Ferguson \& Beveridge (2009) also found that, although stem-girdling blocks polar auxin transport, this not always causes bud outgrowth, because it also depends on the nutritional status of the bud (Barbier et al., 2019). This, and the lower temperature for the third date of treatment, might also contribute to the lack of bud release (Fig. 3).

As a result of girdling, vegetative growth occurred precociously during late summer, and flowers were surprisingly produced in the ON-girdled shoots in the following spring, whereas the ungirdled ON shoots displayed the expected behaviour: the natural reset of vegetative growth, instead of flowering, and its transition to an OFF state (Fig. 4). The girdled shoots G1 and G2 produced 45 flowers on average, and flowers appeared only on the axillary buds formed in the new autumn shoots. The nodes from ON-girdled shoots that did not produce vegetative shoots in autumn, did not flower the following spring (Fig. 4). Accordingly, as the late-autumn girdling $(\mathrm{ON}+\mathrm{G} 3)$ did not induce sprouting (Fig. 3), neither did flowering (data not shown). These results suggested that flowering in the fruiting shoots was not directly due to girdling but to sprouting. Conversely, all the buds from OFF shoots had the ability to flower, even without having sprouted in autumn. In summary, these results suggested that flowering must necessarily be preceded by vegetative development. In natural conditions after an $\mathrm{ON}$ season, this vegetative growth generates OFF branches in spring, and the new buds flower 1 yr later, whereas girdling of $\mathrm{ON}$ shoots advanced vegetative growth and flowering by one season.

\section{H3K27me3 in the CCMADS19 locus and its repression allow flowering in the new vegetative shoots}

According to the above results, girdling of fruit peduncle provides an ideal experimental set-up to address the mechanism by which the epigenetic status of CcMADS19 is reset during vegetative growth. Our previous results comparing ON and OFF trees
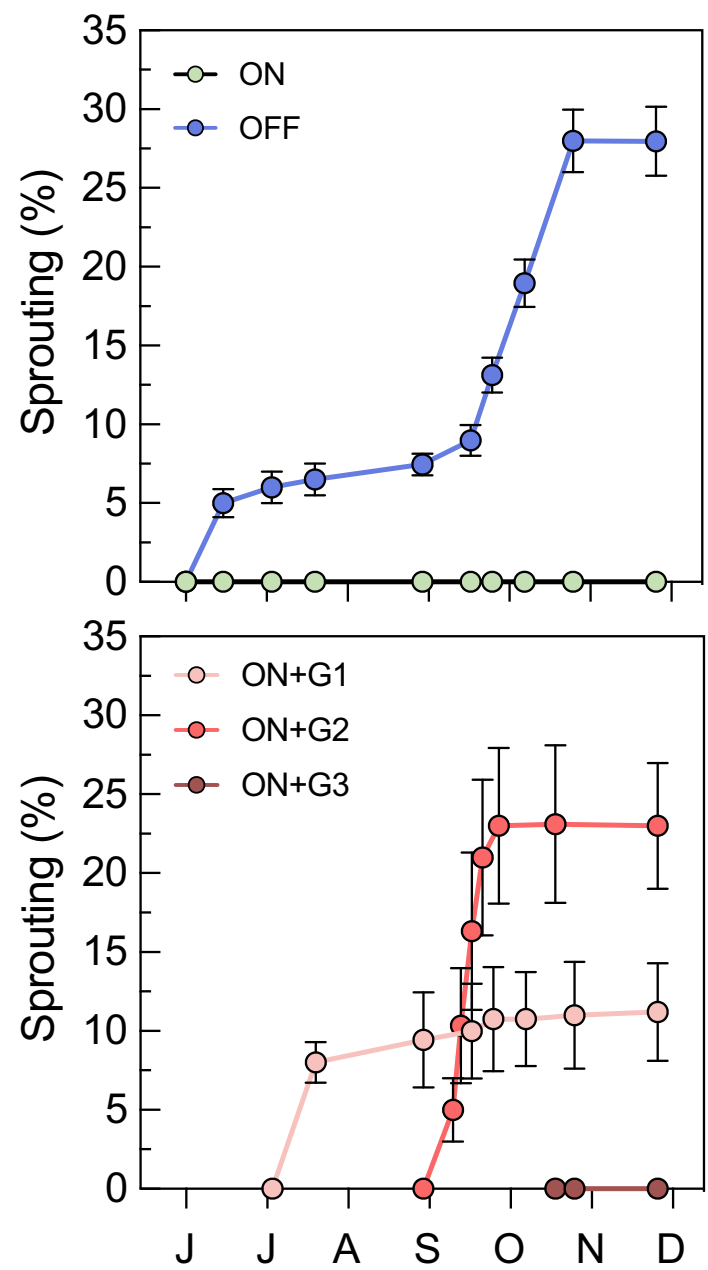

Fig. 3 Effect of fruit-peduncle girdling on the time-course of axillary bud sprouting of tangor 'Nadorcott' (Citrus clementina $\times$ Citrus sinensis) during summer and fall. Girdling was performed on early summer (G1), late summer (G2) and early fall (G3). Data are means \pm standard error of 50 shoots per treatment distributed in 10 trees. ON: shoot with an apical fruit; OFF: nonfruiting shoot.

suggested that axillary buds were refractory to the CcMADS19 epigenetic activation induced on neighbour leaves by the presence of the fruit. Contrary to the leaves, where the CcMADS19 locus was enriched in the activator mark $\mathrm{H} 3 \mathrm{~K} 4 \mathrm{me} 3$, this locus was enriched in the repressive mark H3K27me3 in the buds (Agustí et al., 2020). Therefore, we hypothesised that new shoots and leaves generated by these buds would inherit the repressed state of CcMADS19.

In agreement with this hypothesis, we found that the expression of CcMADS19 was upregulated in the leaves of ON shoots, but not in the leaves of OFF, or in the new leaves of girdled ON shoots $(\mathrm{ON}+\mathrm{G} 2)$ (Fig. 5a). Accordingly, with the concurrence of floral inductive signals in winter, CiFT3 expression was maintained low in the leaves of ON shoots, compared with those of $\mathrm{OFF}$ or $\mathrm{ON}+\mathrm{G} 2$ shoots (Fig. 5b). These results confirmed that flowering in the following spring was preceded by silencing of CcMADS19 in $\mathrm{ON}+\mathrm{G} 2$ shoots. To investigate how this silencing occurred, we examined the deposition of $\mathrm{H} 3 \mathrm{~K} 27 \mathrm{me} 3$ mark in 
(a)

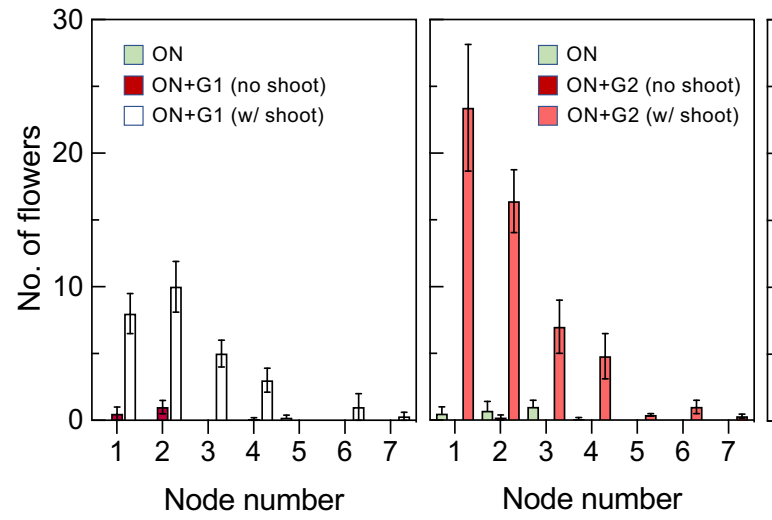

(c)
Fig. 4 Effect of fruit-peduncle girdling on summer on the flowering distribution along the ON-shoot of tangor 'Nadorcott' (Citrus clementina $\times$ (itrus sinensis) in the next spring. Girdling was performed on early summer (G1) (a) and late summer (G2) (b). OFF shoots (c) were used for comparison. Flowering was evaluated separately in shoots that had sprouted (w/shoot) or not (no shoot) in autumn. Data are means \pm standard error of 50 shoots per treatment distributed in 10 trees. ON: shoot with an apical fruit; OFF: shoot without fruit.
Fig. 5 CCMADS19 active/repressed state correlates with changes in histone methylation. (a) and (b) Relative expression of CCMADS19 and CiFT2 in adult leaves from ON and OFF shoots, and young leaves from $\mathrm{ON}+\mathrm{G} 2$ shoots. (c) H3K27me3 levels in the same leaves determined by ChIP of two regions located on the promoter of the CCMADS-box19 locus. (d) Relative expression in adult leaves from $\mathrm{ON}$ shoots and young leaves from $O N+G 2$ shoots of CCELF6, CCATX1-L, CCCLF, CCVIN3 genes determined by RT-qPCR. Data correspond to leaves of tangor 'Nadorcott' (Citrus clementina $\times$ Citrus sinensis) sampled at early autumn before the inductive period (1 October). Data are means \pm SE. Asterisks indicate statistical significance in Student's $t$ test $(P<0.01, n=3)$; ns, not significant. (a)

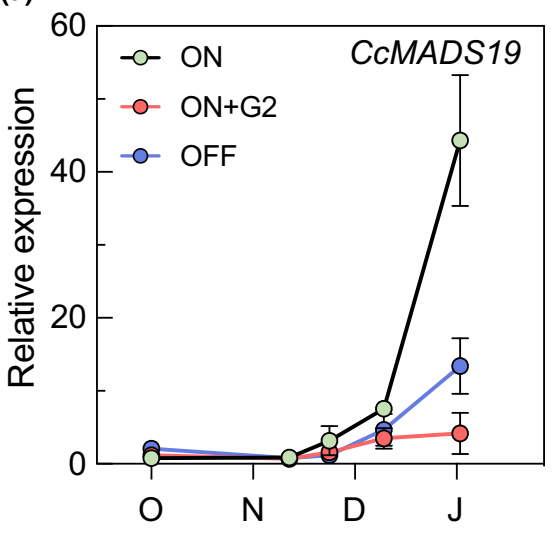

(c)
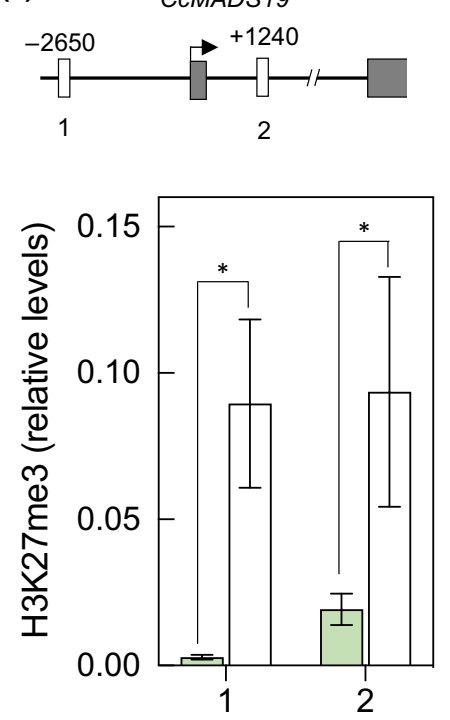

(d) (b)
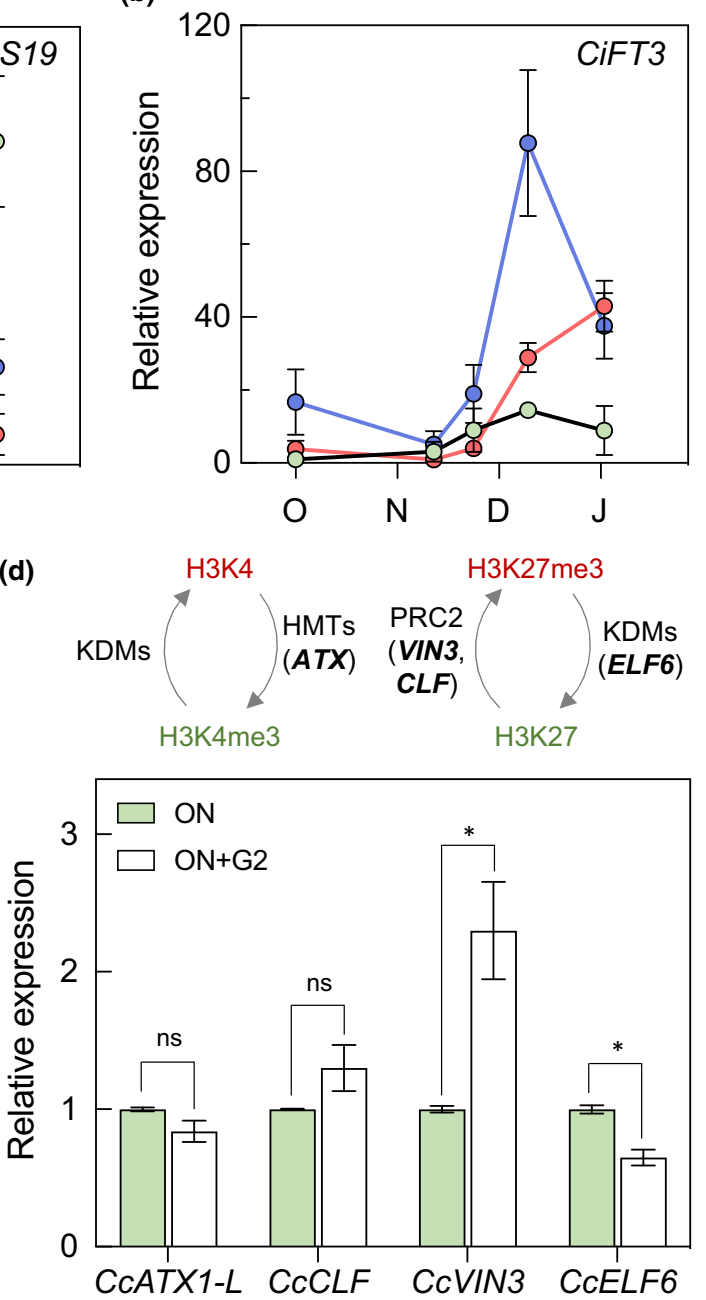

this locus, in the adult leaves of $\mathrm{ON}$ and the new leaves of the $\mathrm{ON}+\mathrm{G} 2$ shoots. As predicted by the behaviour previously observed in buds (Agustí et al., 2020), young leaves of ON+G2 shoots showed significant enrichment of the H3K27me3 in two different regions of the CcMADS19 promoter, compared with the leaves from ON shoots (Fig. 5c).
Increase of $\mathrm{H} 3 \mathrm{~K} 27 \mathrm{me} 3$ levels was further supported by the study of the expression of several Citrus orthologues encoding histone methyltransferases and demethylases (Figs S3, S4; Table S1). It has been reported that the PHD protein member VIN3 and the PRC2 histone methyl-transferase CURLY LEAF $(C L F)$ are required for the deposition of $\mathrm{H} 3 \mathrm{~K} 27 \mathrm{me} 3$ marks in 
the Arabidopsis $F L C$ locus to repress its expression during vernalisation (De Lucía et al., 2008; de Lucas et al., 2016). Interestingly, we found an increase in CcVIN3 expression in the young leaves of $\mathrm{ON}+\mathrm{G} 2$ shoots, compared with those of ON shoots (Fig. 5d). This was in marked contrast with the absence of any differential effect in the expression of CCATX1 (homologue of TRITHORAX1) whose Arabidopsis orthologue catalyses the deposition of the H3K4me3 activator mark (Pien et al., 2008), or the minor reduction in CcELFG (EARLY FLOWERING O) expression in young leaves of $\mathrm{ON}+\mathrm{G} 2$ shoots (Fig. $5 \mathrm{~d}$ ). The Arabidopsis ELF6 protein is a $\mathrm{H} 3 \mathrm{~K} 27 \mathrm{me} 3$ demethylase involved in $F L C$ reactivation after vernalisation (Crevillén et al., 2014). These results suggested that the maintenance of CcMADS19 silencing in newly formed shoots and leaves could be primarily due to enhanced activity of CcVIN3 and, consequently, the PRC2 complex and possibly to the decrease in $C c E L F G$ expression.

Our results are in line with the mode of flowering regulation proposed for Arabidopsis and A. alpina, in which FLC and PEP1 silencing is promoted by vernalisation and mediated by H3K27me3 (De Lucía et al., 2008; Wang et al., 2009). Methylation begins during vernalisation in the nucleation region of the FLC locus and, after cold exposure, the $\mathrm{H} 3 \mathrm{~K} 27 \mathrm{me} 3$ mark spreads over the entire locus to ensure maintenance of long-term silencing (De Lucía et al., 2008). In Citrus, resetting of the competence to respond to flowering inductive signals would then be achieved by the maintenance of CcMADS19 silencing in the buds despite their proximity to apical fruits, and subsequent vegetative growth of new shoots and leaves derived from these buds. It is noteworthy that the correlation between CcVIN3 and H3K27me3 levels in the CcMADS19 locus seems to occur in a context unrelated with vernalisation (i.e. October, before cold). While, in Arabidopsis, VIN3 induction is triggered by exposure to low temperature (Hepworth et al., 2020), and modulated by the circadian clock (Hepworth etal., 2018), CcVIN3 expression would be linked to a developmental phase transition, such as restarting vegetative growth from dormant buds. However, two alternatives are possible too. First, it cannot be ruled out that $C c V I N 3$ is activated by environmental signals that accompany the phase transition, which would resemble the regulation of VIN3 in Arabidopsis. And second, it has been suggested that a threshold level of metabolic activity or cell division is required for vernalisation (Michaelis \& Amasino, 2000); therefore, an attractive hypothesis is that sprouting could also be necessary to establish $\mathrm{H} 3 \mathrm{~K} 27 \mathrm{me} 3$ marks on CcMADS19.

In conclusion, vegetative growth resets the fruit-dependent inhibition of flowering through epigenetic reprogramming of CcMADS19, which explains how the ON Citrus tree is able to re-establish the flowering ability during the next OFF season, therefore the new buds generated in spring on these vegetative shoots flower $1 \mathrm{yr}$ later. But girdling of $\mathrm{ON}$ shoots advanced vegetative growth and buds flower by one season (Fig. 6). Results suggest the idea that flowering must necessarily be preceded by

Season 1

Season 2

Season 3

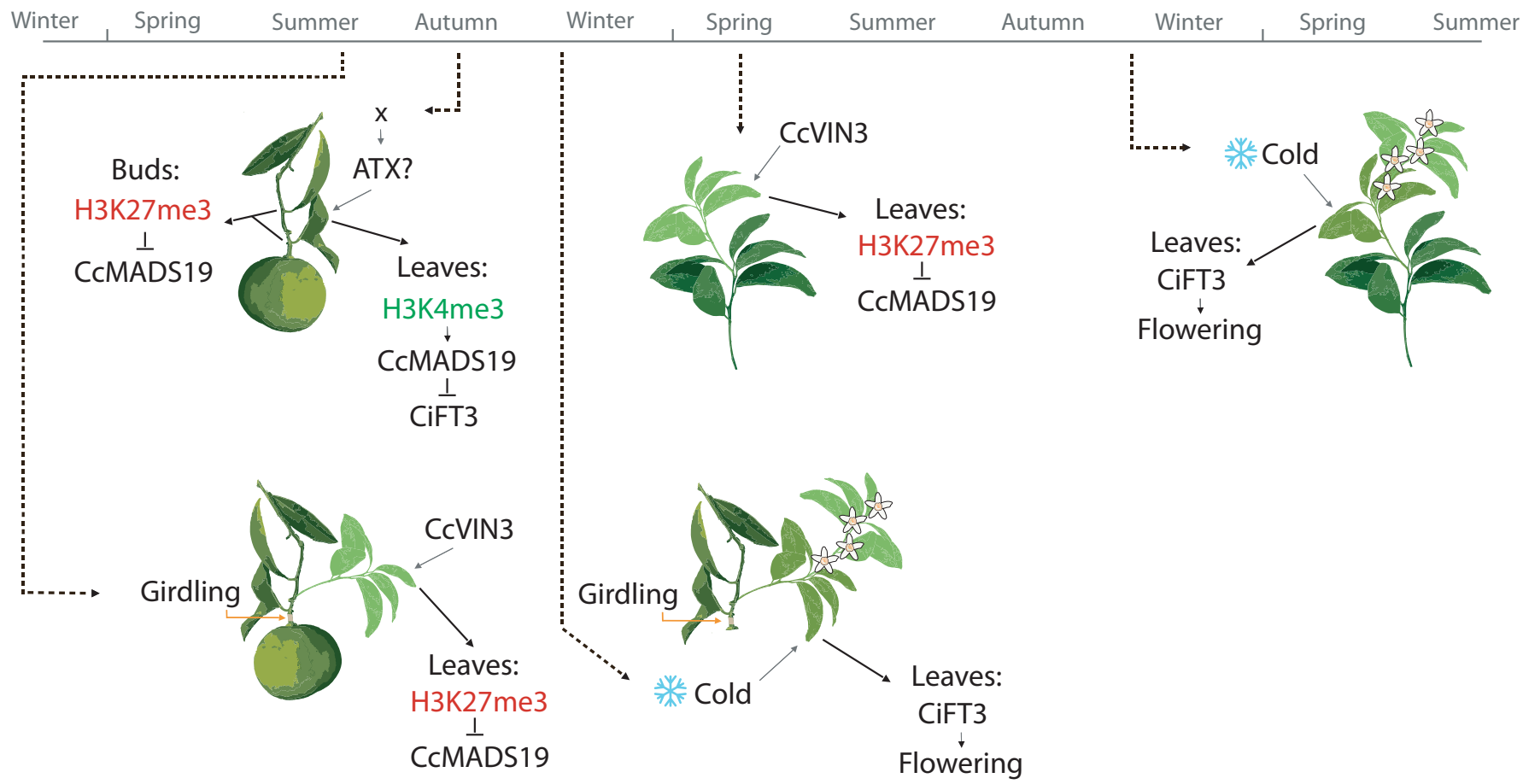

Fig. 6 Diagramatic representation of the reversion of fruit-dependent inhibition of flowering in the tangor 'Nadorcott' (Citrus clementina $\times$ Citrus sinensis). Fruit promotes H3K4 trimethylation of CCMADS19 in nearby leaves to inhibit the response to floral inductive signals in winter, but the repressive $\mathrm{H} 3 \mathrm{~K} 27 \mathrm{me} 3$ is maintained in buds. In spring, buds sprout and the newly formed leaves maintain the repressed state of CcMADS19 thanks to enhanced CCVIN3 activity, so that they become responsive to subsequent floral inductive cold temperatures. Summer girdling advances bud sprouting to early autumn instead of the following spring, and the new leaves are ready to respond to cold temperatures in the immediate winter, causing the induction of the florigen encoded by CiFT3. 
vegetative development. Given that the growing fruit represses lateral bud outgrowth, the renewal of the vegetative shoots mainly occurs after the end of the ON season, with harvest, therefore giving rise to biennial bearing. The horticultural consequence of the latter is that promoting vegetative growth (for instance, by mechanical pruning) mitigates yield alternation in Citrus (Mesejo et al., 2020).

\section{Acknowledgements}

The work described in this paper was partially supported by grants PROMETEO/2019/021 Generalitat valenciana (MAB). We also acknowledge financial support by the Spanish Ministerio de Ciencia, Innovación y Universidades through grant no. RTI2018-101303-B-100 (CM).

\section{Author contributions}

MA, CM, EPM and MB planned and designed the research; $\mathrm{AM}, \mathrm{AMF}, \mathrm{CR}$ and DJI performed experiments and conducted fieldwork; MdL, AMF carried out biochemical analyses; MA, $\mathrm{CM}, \mathrm{MdL}, \mathrm{EPM}$ and $\mathrm{MB}$ analysed data; and MA, CM and MB wrote the manuscript. MA, MB and CM contributed equally.

\section{ORCID}

Manuel Agustí (iD https://orcid.org/0000-0002-4271-6299

Miguel A. Blázquez (iD https://orcid.org/0000-0001-5743-0448

Domingo J. Iglesias (D https://orcid.org/0000-0001-8596-6100

Miguel Lucas de (iD https://orcid.org/0000-0002-6544-6404

Amparo Martínez-Fuentes (D) https://orcid.org/0000-0002-

8594-4953

Andrés Marzal (D) https://orcid.org/0000-0001-6621-4915

Carlos Mesejo (iD https://orcid.org/0000-0002-6984-0775

Carmina Reig (DD https://orcid.org/0000-0002-1911-6834

\section{References}

Agustí M, Almela V, Pons J. 1992. Effects of girdling on alternate bearing in citrus. Journal of Horticultural Science 67: 203-210.

Agustí M, Mesejo C, Muñoz-Fambuena N, Vera-Sirera F, de Lucas M, Martínez-Fuentes A, Reig C, Iglesias DJ, Primo-Millo E, Blázquez MA. 2020. Fruit-dependent epigenetic regulation of flowering in Citrus. New Phytologist 225: 376-384.

Andrés F, Coupland G. 2012. The genetic basis of flowering responses to seasonal cues. Nature Reviews Genetics 13: 627-639.

Bangerth F, Li CJ, Gruber J. 2000. Mutual interaction of auxin and cytokinins in regulating correlative dominance. Plant Growth Regulation 32: 205-217.

Barbier FF, Dun EA, Kerr SC, Chabikwa TG, Beveridge CA. 2019. An update on the signals controlling shoot branching. Trends in Plant Science 243: 220236.

Bratzel F, Turck F. 2015. Molecular memories in the regulation of seasonal flowering: from competence to cessation. Genome Biology 16: 1-14.

Crevillén P, Yang H, Cui X, Greeff C, Trick M, Qiu Q, Cao X, Dean C. 2014. Epigenetic reprogramming that prevents transgenerational inheritance of the vernalized state. Nature 515: 587-590.

de Lucas M, Pu L, Turco G, Gaudinier A, Morao AK, Harashima H, Kim D, Ron M, Sugimoto K, Roudier F et al. 2016. Transcriptional regulation of
Arabidopsis polycomb repressive complex 2 coordinates cell-type proliferation and differentiation. Plant Cell 28: 2616-2631.

de Lucia F, Crevillen P, Jones AME, Greb T, Dean C. 2008. A PHD-polycomb repressive complex 2 triggers the epigenetic silencing of FLC during vernalization. Proceedings of the National Academy of Sciences, USA 105: 1683116836.

Ferguson BJ, Beveridge CA. 2009. Roles for auxin, cytokinin, and strigolactone in regulating shoot branching. Plant Physiology 149: 1929-1944.

Finnegan EJ, Dennis ES. 2007. Vernalization-induced trimethylation of histone $\mathrm{H} 3$ lysine 27 at FLC is not maintained in mitotically quiescent cells. Current Biology 17: 1978-1983.

Goldschmidt EE, Sadka A. 2021. Yield alternation: horticulture, physiology, molecular biology, and evolution. Horticultural Reviews 48: 363-418.

Goren R, Huberman M, Goldschmidt EE. 2010. Girdling: physiological and horticultural aspects. Horticultural Reviews 30: 1-36.

Guardiola JL, Monerri C, Agusti M. 1982. The inhibitory effect of gibberellic acid on flowering in Citrus. Physiologia Plantarum 55: 136 142.

Hepworth J, Antoniou-Kourounioti RL, Berggren K, Selga C, Tudor E, Yates B, Cox D, Collier-Harris BR, Irwin JA, Howard M et al. 2020. Natural variation in autumn expression is the major adaptive determinant distinguishing Arabidopsis FLC haplotypes. eLife 9: e57671.

Hepworth J, Antoniou-Kourounioti RL, Bloomer RH, Selga C, Berggren K, Cox D, Collier-Harris BR, Irwin JA, Howard M, Säll T et al. 2018. Absence of warmth permits epigenetic memory of winter in Arabidopsis. Nature Communications 9: 1-8.

Hoijemberg M, Cerdán PD. 2020. Epigenetic accounting of a previous harvest. New Phytologist 225: 10-12.

Hou XJ, Liu SR, Khan G, Hu C-G, Zhang J. 2014. Genome-wide identification, classification, expression profiling, and SSR marker development of the MADS-box gene family in Citrus. Plant Molecular Biology Reporter 32: 28-41.

Krasniqi A, Damerow KA, Blanke MM. 2013. Quantifying key parameters as elicitors for alternate fruit bearing in cv. 'Elstar' apple trees. Plant Science 212 $10-14$.

Lázaro A, Obeng-Hinneh E, Albani MC. 2018. Extended vernalization regulates inflorescence fate in Arabis alpina by stably silencing PERPETUAL FLOWERING1. Plant Physiology 176: 2819-2833.

Lee J, He K, Stolc V, Lee H, Figueroa P, Gao Y, Tongprasit W, Zhao H, Lee I, Deng XW. 2007. Analysis of transcription factor HY5 genomic binding sites revealed its hierarchical role in light regulation of development. Plant Cell 19: 731-749.

Martínez-Fuentes A, Mesejo C, Reig C, Agustí M. 2010. Timing of the inhibitory effect of fruit on return bloom of 'Valencia'sweet orange (Citrus sinensis (L.) Osbeck). Journal of the Science of Food and Agriculture 90: 19361943.

Mesejo C, Martínez-Fuentes A, Reig C, Balasch S, Primo-Millo E, Agustí M. 2020. Mechanical pruning attenuates alternate bearing in 'Nadorcott' mandarin. Scientia Horticulturae 261: 108993.

Michaels SD, Amasino RM. 2000. Memories of winter: vernalization and the competence to flower. Plant, Cell \& Environment 23: 1145-1153.

Monselise SP, Goldschmidt EE. 1982. Alternate bearing in fruit trees. Horticultural Reviews 4: 128-173.

Nelson JD, Denisenko O, Sova P, Bomsztyk K. 2006. Fast chromatin immunoprecipitation assay. Nucleic Acids Research 34: e2.

Pien S, Fleury D, Mylne JS, Crevillen P, Inzé D, Avramova Z, Dean C, Grossniklaus U. 2008. ARABIDOPSIS TRITHORAX1 dynamically regulates FLOWERING LOCUS C activation via histone 3 lysine 4 trimethylation. Plant Cell 20: 580-588.

Tukey HB. 1922. Alternate bearing of fruit trees. Science 55: 241.

Verreynne JS, Lovatt CJ. 2009. The effect of crop load on budbreak influences return bloom in alternate bearing 'Pixie' mandarin. Journal of the American Society for Horticultural Science 134: 299-307.

Wang R, Farrona S, Vincent C, Joecker A, Schoof H, Turck F, Alonso-Blanco C, Coupland G, Albani MC. 2009. PEP1 regulates perennial flowering in Arabis alpina. Nature 459: 423-427. 


\section{Supporting Information}

Additional Supporting Information may be found online in the Supporting Information section at the end of the article.

Fig. S1 Experimental approach to force vegetative development in the axillary buds during the $\mathrm{ON}$ season.

Fig. S2 Effect of fruit-peduncle girdling on axillary bud IAA concentration in $\mathrm{ON}$ shoots with an apical fruit.

Fig. S3 Phylogenetic relationships between histone demethylase genes of Citrus sinensis, Citrus clementina and Arabidopsis thaliana.
Fig. S4 Phylogenetic relationships between VIN3 orthologues of several species.

Table S1 Primer sequences used in this study.

Please note: Wiley Blackwell are not responsible for the content or functionality of any Supporting Information supplied by the authors. Any queries (other than missing material) should be directed to the New Phytologist Central Office. 